\title{
Effect of physical activities program on stress level among elderly women
}

Somaya Abou Abdou :Assistant Professor of Psychiatric -Mental Health Nursing, Faculty of Nursing, Suez Canal University, Ismailia

Ola Ali Abd El-Fatah Ali Saray:lecturer of Psychiatric Mental Health Nursing, Faculty of Nursing, Assiut University

Hanaa Mouhktar Ibrahim:lecturer of Gerontological Nursing, Faculty of Nursing, Assiut University

Saieda Abd-Elhameed Abd-Elaziz:lecturer of Gerontological Nursing, Faculty of Nursing, Assiut University

\begin{abstract}
The health benefits of physical activity and exercise are well documented and these effects could help elderly individual. This study aimed to assess stress level and implement Physical activities program to elevate stress among elderly women. Subjects and method: This study was conducted at geriatric clubs at Assiut city. The study included forty two elderly women randomly assigned to intervention Each elderly women was evaluated through bio socio demographic characteristics and Perception of life stressors questioners. Results showed that there were statistically significant improvement in pre and post physical activities program on stress level among elderly women. The study concluded that application physical activity program for elderly women with stress have significant therapeutic effect on stress symptom among elderly women. Recommendation: Physical exercises to be apart of activities of daily living for elderly women and health education for elderly women about important of regular Physical exercises.
\end{abstract}

Key words: physical activity, stress level, elderly women 


\section{Tanta Scientific Nursing Journal}

\section{Introduction:}

The resent research proved that there an integration between psychiatric mental health nurse and geriatric nurse from this view found that stress in older adults has unique contributing factors, such as the loss of an elderly spouse or friends. Living alone can increase the sense of isolation, retirement, new social situations sometimes the simple tasks of everyday life can cause stress in those and experience physical or medical limitations. The effects of stress can sometimes exacerbate health conditions and causing additional worry ${ }^{(\mathbf{1}) \text {. }}$

Barneswho reported that increasing the lifetime of a population is often a marker pen of a country's success. With the backwardation of the population over 65 of old age enlarging, managing the health and independence of this population is an business affair. Advancing seniority is associated with aggravate level of stress lead to a decrease in cognitive function that in the end affects quality of life. Understanding potentially averse execution of aging on brain, blood stream and cognition may be friend to finish competent strategies to mitigate these effects on the population. Physical activity may be strategies to intercept or delay cognitive decline and de escalate stress ${ }^{(2) .}$

Stress is highly prevalent among elderly individuals and is associated with detrimental effects on mood, appetite and cognition. Furthermore, stress in aging females remains a highly relevant. Old female it led to weight loss, deregulated locomotion and memory impairment. The physical activity interventions that could reduce the burden of stress in female in late life ${ }^{(3)}$ According to the American Institute of Stress reported that sixty percent of all human illnesses are caused by stress. Female elderly experience extreme stress, which means these folks may experience heart palpitations, depression, and shaking as a result of the stress ${ }^{(4) \text {. }}$

Karen Larson who define stress as state of threatened homeostasis, which is counteracted by adaptive processes involving affective, physiological, biochemical, and cognitive-behavioral responses in an attempt to regain homeostasis. Stress can result from external factors (e.g., events, environment) or from internal factors (e.g., expectations, attitudes and feelings). Stress often occurs in response to situations that are perceived as 


\section{Tanta Scientific Nursing Journal}

being difficult to handle or threatening. Common causes for stress (called stressors) include illness, injury, fear, and anxiety ${ }^{(5)}$.

According to Butler\& Alia they describe physical manifestation of stress include dryness of the throat and mouth, butterflies in the stomach, diarrhea, and vomiting, loss or excessive appetite, pounding of the heart, weakness, dizziness, tension, alertness, trembling, nervous tics, nervous laughter, grinding of teeth, insomnia, nightmares, or other sleep difficulties, excessive perspiration, increased frequency of urination, muscle tension and migraine headaches, and pain in the neck or lower back ${ }^{(1)}$.

Kolehmainen and Sinha they described psychological manifestations of stress, which includes: increased forgetfulness of names, places or other things that normally come naturally and lack of concentration while physical signs of stress include body aches and pains or increased episodes of illness $^{(\boldsymbol{( 6 )}}$. (Changes in sleeping patterns either trouble falling asleep or interrupted nighttime sleep are signal significant of stress). Some elderly may exercise poor judgment, such as excessive spending when they are already on a limited budget isolate themselves from others, and refusing to socialize or participate in activities they used to enjoy ${ }^{(7)}$.

Chiesa, \& Serretti they reported that an important step in stress management for female elderly is physical activity. Thus, physical activity can help avoid the damage to cognitive function, cognitive speed and auditory/visual attention (8). In addition to the studies found that physical activity is a potent antidepressant, anxiolytic (combats anxiety), and sleeping aid for elderly women. Effective intervention that deserves consideration is physical activity, an adjunct that has many well established health benefits and may serve to enhance quality of life ${ }^{(9-10)}$.

World Health Organization defined Physical activity as any bodily movement produced by

skeletal muscles that require energy expenditure. Alternatively, any musculoskeletal activity increases the organism's energy expenditure above its resting rate ${ }^{(11)}$.

Kendal who reported that there are four kind of activity for older adults Aerobic exercises that increase breathing and heart rate, strength exercises, balance exercises, flexibility/stretching exercises ${ }^{(\mathbf{1 2})}$. 
Gorczynski \& Faulkner found that regular physical activity is thought to improve both physical and mental health. Regular physical activity can help elderly to improve their physical and mental health and wellbeing, thus contributing positively to health (13). According to the Anxiety and Depression Association of Americaexercise and other physical activity produce endorphins chemicals in the brain that act as natural painkillers and also improve the ability to sleep, which in turn reduces stress. stress it is also involved in the development and course of many diseases, stress significantly affects the course of diseases ${ }^{(\mathbf{1 4}, 15)}$.

Aim of the study was to :Investigate stress level and implement Physical activities program to elevate stress among elderly women.

\section{Research hypotheses}

Stress among elderly women after

implementation of Physical activities

program expected to be decreased

\section{Subject and method:}

\section{Research Design:-}

A Quasi experimental research design was used in the study.

Setting:-The study was carried out at the geriatric clubs on Assiut city in which all geriatric committee of Assiut organized three meeting per week for elderly this committee include Elgamia El sharea, cultural center to enhance social interaction for elderly with others. Thereby implement the study in geriatric club.

Sample :-Convenience sampling consists of forty two of elderly women was randomly selected of physical activity program.

\section{Inclusion Criteria:-}

1. Female elderly

2. Female who physically fit and accepted to participate in physical activity program.

\section{Exclusion Criteria:-}

1. Geriatric individual with medical disorders that intervene with physical activity (e.g. severe heart disease, severe pulmonary disease, or fractures...).

2. Patient with history of surgical operation (e.g. open heart or herniorrhaphy )

3. Patients who unfit for physical activity (might be due to osteoarthritis).

\section{Permission to conduct the study:}

An official permission was obtained from the Dean of the faculty of nursing-Assiut University directed to directors of the geriatric clubs at Assiut city to accept to 
start of the research at geriatric clubs of Assiut city.

\section{Ethical consideration:}

An oral consent was obtained from all female elderly before collecting data. Explain to each elderly aim of study. No harmful maneuver and no hazards were anticipated. Confidentiality was maintained during all steps of the study.

Tools of the study: Each elderly individuals was evaluated through two tools:

\section{Tool 1: include two parts:}

Part I: Biosociodemographic data sheet Included name, age, sex, level of education, occupation, marital status...etc

Part II: medical history such as:- D.M, Hypertension, Heart disease

\section{Tool II: Perception of life stressors} questioners (16) revised version of social readjustment rating scale ${ }^{(17) .}$

This scale contained 43 items, based on the premise that good and bad events in ones life can increase stress levels and make one more susceptible to illness and mental health problems. Each event should be considered if it has taken place in the last 12 months. Since the scale was developed in 1967, perception of stress changed. To more accurate measure life change events were viewed as more stressful depending on its severity. Scoring of this scale categorized as: low $<149$, moderate150- 299, high $>300$.

\section{Method}

Pilot study: pilot study was conducted on 10 elderly, who were participated to tested the tool content of clarity and the time needed for filling the tool. Were excluded from total sample.

\section{Phases for physical activities program for elderly:}

The following four phases were carried out to the physical activities program for elderly women included the following:

\section{1- Assessment phase:}

The elderly women assess according to bio socio demographic tools, Perception of life stressors questioners, and assess the physical fitness for elderly activity, where any abnormalities of posture and gait were noted, and inquiry about previous or ongoing orthopedic, neurological, cardiovascular, or respiratory problems. Muscles flexibility evaluated by assessment of full body range of motion thorough joint, neck, four limbs movements, and the flexibility of the trunk muscles during walking

\section{2-Planning phase:}

The planning phase for physical activities program for elderly consisted of one session 


\section{Tanta Scientific Nursing Journal}

every other day (three times per week) and lasts for four weeks. Each session lasted for 15-30 minutes and consists of 4 parts. Part one began with a few minutes of relaxed breathing, performed in sitting positions, patients were instructed to take diaphragmatic breathing. Part two aerobic training is also called (endurance training) includes walking and stair climbing. An elderly women can walk almost anywhere without any special skills or equipment except a good pair of shoes. followed by Flexible physical activity as part three included four physical activity as neck rotation, neck stretch, sideways bend, and calf stretch. Part four strengthening physical activity were adapted to accommodate elderly individual needs which included five physical activity as sit to stand, mini squats, calf raises, sideways leg lift, and leg extension.

\section{3-Implementation phase:}

The intervention phases for physical activities program for elderly consisted of session every other day (three times per week) and lasts for four weeks. Each session lasted for 15-30 minutes and consists of 4 parts. Part one began with a few minutes of relaxed breathing, performed in sitting positions, patients were instructed to take diaphragmatic breathing.

Part two: aerobic training (endurance training) includes walking and stair climbing. An elderly women can walk with comfortable pair of shoes.

Part three: flexible physical activity included four physical activity first: Neck rotation in which the elderly instruct to sit upright with shoulders down. Look straight ahead slowly turn head towards left shoulder as far as is comfortable hold for five seconds and return to starting position repeat going right. Do three rotations on each side. Second: Neck stretch sitting upright, look straight ahead and hold left shoulder down with right hand slowly and then tilt head to the right while holding shoulder down repeat on the opposite side. Hold each stretch for five seconds and repeat three times on each side. Third: Sideways bend the elderly women stand upright with feet hip-width apart and arms by sides. slide left arm down side as far as is comfortable and lower arm, stretch shoulder on the opposite hip. Repeat with right arm down right side. perform three on each side. Fourth: Calf stretch Instruct elderly women to place hands against a wall for stability bend the right leg 


\section{Tanta Scientific Nursing Journal}

and step the left leg back at least a foot's distance, keeping it straight both feet should be flat on the floor. The left calf muscle is stretched by keeping the left leg as straight as possible and the left heel on the floor. Repeat with the opposite leg and perform three on each side.

\section{Part four strengthening physical activity} were adapted to accommodate elderly individual needs which included five physical activity first: Sit to stand teach elderly women to sit on the edge of the chair, feet hip-width apart. Lean slightly forwards. Stand up slowly, using legs, not arms. Keep looking forwards. Stand upright before slowly sitting down, bottom-first. Second: Mini squats elderly women instructed to Rest hands on the back of the chair for stability and stand with feet hipwidth apart. Slowly bend knees as far as is comfortable, keeping them facing forwards. Keep back straight at all times. Gently come up to standing, squeezing your buttocks and repeat five times. Third: Calf raises teach elderly women to rest hands on the back of a chair for stability. Lift both heels off the floor as far as is comfortable. The movement should be slow and controlled. Repeat five times. Fourth: Sideways leg lift
Put hands on the back of a chair for stability. Raise left leg to the side as far as is comfortable, keeping back and hips straight. Avoid tilting to the right. Return to the starting position. raise right leg to the side as far as possible. Raise and lower each leg five times. Fifth: Leg extension teach elderly women to put hands on the back of a chair for stability. Standing upright, raise left leg backwards, keeping it straight. Avoid arching back should feel the effort in the back of thigh and bottom. Repeat with the other leg and repeat five times with each leg.

\section{Schedule of the program:}

The schedule of Physical activities program for elderly includes (time and number of sessions, teaching method). The teaching place and the facilities were checked for appropriateness. Number of sessions was 12 sessions, three sessions per week for 15-30 minute. The program conducted at the geriatric clubs at Assiut city. Physical activity implemented during four weeks in minutes duration offered 3 times per week. Each session of physical activity consisted of four parts and was conducted by the researcher. 


\section{Physical activities program among elderly women:}

The designed program included the following: the duration of physical activities program for four weeks work for 15-30 minutes duration offered 3 times per week to elderly women from the first of October to 30th of December 2017. The designed program included the following: the duration of physical activities program for four weeks work for 15-30 minutes duration offered 3 times per week to elderly women from the first of October to 30th of December 2017.

Each session of the nursing intervention of physical activity program consisted of four parts and conducted by the researchers. The sessions begin with:

Part1-Relaxed deep breathing for 5minutes.

Part 2-Aerobic training for 5 minutes.

Part 3- Flexible physical activity 5-10 minutes.

Part 4-Strengthening physical activity 5-10 minutes.

Methods of teaching used in the program: Methods of teaching have been used in each session includes demonstration, and role play

\section{Media used in the program:}

Media have been used in each session includes demonstration, video, and Posters.

\section{Fourth: - Evaluation phases:}

Evaluation phases of the impact of Physical activities program for elderly women used two time one before the program By using bio socio demographic tools and perception of life stressors questioners and second time immediate post program by using perception of life stressors questioners.

\section{Statistical method:}

The data were tabulated and statistical analysis was performed with statistical package for social science (SPSS) version 18 (18). Comparison between studied groups was performed with frequency, chisquare, independent \& paired $\mathrm{T}$ test and ANOVA test. The significance of difference calculates as 0.5

\section{Results}

Table (1): represent that more than three quarter of the studied sample $(78.6 \%)$ their ages ranged from 60 to 74 years with mean of age (69.4+5.5(60-79), while 64.2\% were widow. As regards educational level, it was observed that $(40.5 \%)$ had secondary school. Concerning residence the vast majority of them $(92.9 \%)$ live in the urban 


\section{Tanta Scientific Nursing Journal}

area. According to occupation, more than half of studied sample(57.1\%)were retired. Regarding family relation it was observed that more than third of studied sample $(45.2 \%)$ had moderate family relation, while friends relation near to half $(47.6 \%)$ were strong relation.

Table (2): represents medical history among elderly women the majority of the studied sample (83.3\%) were don't participating physical exercise and only $16.7 \%$ participating walking exercise. As regards medical history one third of studied sample (33.3\%) were suffering from hypertension.

Figure:(1):illustrates frequency of stress level pre and post physical activity program among elderly women. It shows that 59.5\% elderly women of pre program were have high level of stress, while $2.4 \%$ elderly women of post program were have high level of stress.

Table (3): illustrate that significance of differences among pre and post physical activity program among stressed elderly women. There are statistically significance of differences between pre and post physical activity program among stressed elderly.
Table (4): revealed that significance of differences between stress level and bio socio demographic characteristics pre and post program among elderly women. there is no statistically significant difference between pre \& post stress level and demographic characteristics of studied sample. 
Table (1):Bio socio demographic characteristics of elderly women

\begin{tabular}{|c|c|c|}
\hline Bio socia demographic characteristics & $\begin{array}{c}(n=42) \\
\text { No }\end{array}$ & $\%$ \\
\hline Age & سץ & 78.6 \\
\hline $75-84$ years & 9 & 21.4 \\
\hline $\begin{array}{l}\text { Mean } \pm \text { S.D } \\
\text { Range }\end{array}$ & \multicolumn{2}{|c|}{$\begin{array}{c}69.4+5.5 \\
(60-79)\end{array}$} \\
\hline \multicolumn{3}{|l|}{ Marital status: } \\
\hline \multirow{4}{*}{$\begin{array}{ll}\text { - } & \text { Single } \\
\bullet & \text { Married } \\
\bullet & \text { Widow } \\
\bullet & \text { Divorce }\end{array}$} & 2 & 4.8 \\
\hline & 11 & 26.2 \\
\hline & 27 & 64.2 \\
\hline & 2 & 4.8 \\
\hline \multicolumn{3}{|l|}{ Level of education: } \\
\hline \multirow{3}{*}{$\begin{array}{ll}\text { - } & \text { Basic education } \\
\text { - } & \text { Secondary } \\
\text { - } & \text { University }\end{array}$} & 11 & $r 7.2$ \\
\hline & 17 & 40.5 \\
\hline & 14 & 33.3 \\
\hline \multicolumn{3}{|l|}{ Residence } \\
\hline \multirow{2}{*}{$\begin{array}{ll}\bullet & \text { Rural } \\
\bullet & \text { Urban } \\
\end{array}$} & 3 & 7.1 \\
\hline & 39 & 92.9 \\
\hline \multicolumn{3}{|l|}{ Work } \\
\hline \multirow{2}{*}{$\begin{array}{ll}\text { - } & \text { House wife } \\
\text { - } & \text { Retirement }\end{array}$} & 18 & 42.9 \\
\hline & 24 & 57.1 \\
\hline \multicolumn{3}{|l|}{ Living } \\
\hline \multirow{2}{*}{$\begin{array}{l}\text { - Living with family } \\
\text { - Living alone }\end{array}$} & 21 & 50.0 \\
\hline & 21 & 50.0 \\
\hline \multicolumn{3}{|l|}{ Family relation } \\
\hline \multirow{3}{*}{$\begin{array}{ll}\text { - } & \text { Strong } \\
\text { - } & \text { Moderate } \\
\text { - } & \text { Weak }\end{array}$} & 18 & 42.9 \\
\hline & 19 & 45.2 \\
\hline & 5 & 11.9 \\
\hline \multicolumn{3}{|l|}{ Friends relation } \\
\hline \multirow{3}{*}{$\begin{array}{ll}\text { - } & \text { Strong } \\
\text { - } & \text { Moderate } \\
\text { - } & \text { Weak }\end{array}$} & 20 & 47.6 \\
\hline & 15 & 35.7 \\
\hline & 7 & 16.7 \\
\hline
\end{tabular}


Table (2):Illustrated prevalence of medical history among elderly women

\begin{tabular}{|c|c|c|}
\hline $\begin{array}{c}\text { Medical history among elderly } \\
\text { women }\end{array}$ & $\begin{array}{c}(\mathrm{n}=42) \\
\text { No }\end{array}$ & $\%$ \\
\hline \multicolumn{3}{|l|}{ Practicing physical activity } \\
\hline - Yes, walking & 7 & 16.7 \\
\hline - $\mathrm{No}$ & 35 & 83.3 \\
\hline \multicolumn{3}{|l|}{ Medical history } \\
\hline - Without & 14 & rr.r \\
\hline - with & 28 & 66.7 \\
\hline \multicolumn{3}{|l|}{ Type of disease $(=28)$} \\
\hline - Diabetes mellitus & 9 & 21.4 \\
\hline - Heart disease & 4 & 9.5 \\
\hline - Hypertension & 14 & 33.3 \\
\hline - Cholecyctitis & 1 & 2.4 \\
\hline
\end{tabular}

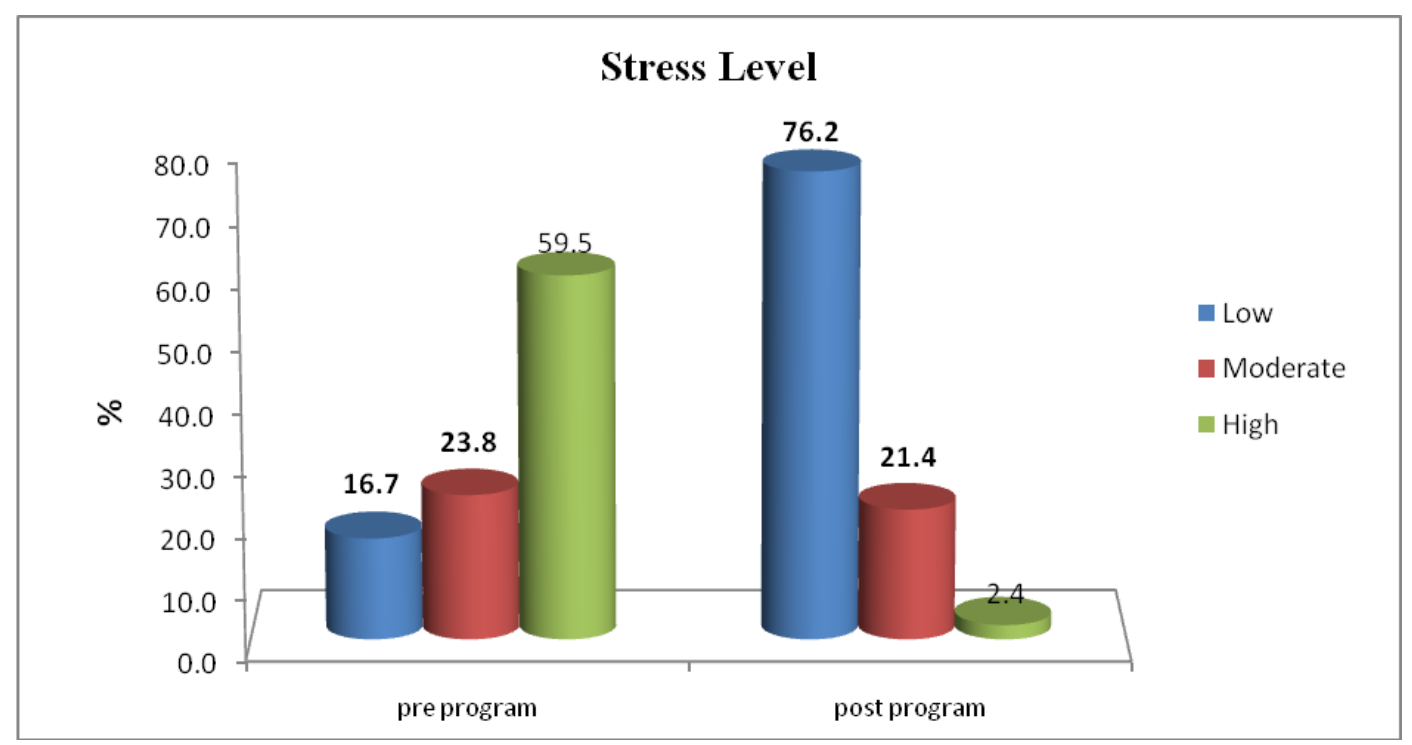

Figure (1): Frequency of stress level pre and post program among elderly women. 
Table(3): Relation between pre and post physical activity program according to stress level of elderly women.

\begin{tabular}{|l|c|c|c|c|c|}
\hline \multirow{2}{*}{ Stress Level } & \multicolumn{2}{|c|}{ Pre program } & \multicolumn{2}{c|}{ Post program } & \multirow{2}{*}{ P.value } \\
\cline { 2 - 5 } & No & $\%$ & No & $\%$ & \\
\hline Low & 7 & 16.7 & 32 & 76.2 & \multirow{2}{*}{$<0.001 * *$} \\
\hline Moderate & 10 & 23.8 & 9 & 21.4 & \\
\hline High & 25 & 59.5 & 1 & 2.4 & \\
\hline Mean \pm SD & \multicolumn{2}{|c|}{$398.7 \pm 211.5$} & \multicolumn{2}{c|}{$164.9 \pm 73.3$} & \\
\hline
\end{tabular}

1- Chi-squire test. ** Highly statistically significant difference $(\mathrm{p}<0.01)$.

Table (4): Significance of differences between stress level and bio socio demographic characteristics pre and post program among elderly women $(n=42)$.

\begin{tabular}{|c|c|c|c|c|c|c|c|c|c|c|c|c|c|c|}
\hline & \multicolumn{7}{|c|}{ Pre program } & \multicolumn{7}{|c|}{ Post program } \\
\hline & \multicolumn{2}{|c|}{ Low } & \multicolumn{2}{|c|}{ Moderate } & \multicolumn{2}{|c|}{ High } & \multirow[b]{2}{*}{ P.value } & \multicolumn{2}{|c|}{ Low } & \multicolumn{2}{|c|}{ Moderate } & \multicolumn{2}{|c|}{ High } & \multirow[b]{2}{*}{ P.value } \\
\hline & No & $\%$ & No & $\%$ & No & $\%$ & & No & $\%$ & No & $\%$ & No & $\%$ & \\
\hline \multicolumn{15}{|l|}{ Age } \\
\hline 60-74 years & 4 & 57.1 & 8 & 80 & 17 & 86 & \multirow{3}{*}{0.453} & 23 & 71.9 & 6 & 66.7 & 1 & 100 & \multirow{3}{*}{0.560} \\
\hline $75-84$ years & 3 & 24.9 & 2 & 20 & 8 & 32 & & 9 & 28.1 & 3 & 33.3 & 0 & 0,00 & \\
\hline Age group & \multicolumn{2}{|c|}{$71.86 \pm 4.74$} & \multicolumn{2}{|c|}{$68.9 \pm 5.17$} & \multicolumn{2}{|c|}{$68.92 \pm 5.93$} & & \multicolumn{2}{|c|}{$68.94 \pm 5.81$} & \multicolumn{2}{|c|}{$70.44 \pm 5.08$} & \multicolumn{2}{|c|}{$74 \pm 0$} & \\
\hline $\begin{array}{l}\text { Marital } \\
\text { statues }\end{array}$ & & & & & & & & & & & & & & \\
\hline Married & 2 & 28.6 & 4 & 40. & 5 & 20.0 & \multirow{4}{*}{0.688} & 6 & 18.8 & 4 & 44.4 & 1 & 100.0 & \multirow{4}{*}{0.321} \\
\hline Divorced & 0 & 0.0 & 0 & 0.0 & 2 & 8.0 & & 2 & 6.3 & 0 & 0.0 & 0 & 0.0 & \\
\hline Widow & 5 & 71.4 & 6 & $\begin{array}{c}60 . \\
0\end{array}$ & 16 & 64.0 & & 23 & 71.9 & 4 & 44.4 & 0 & 0.0 & \\
\hline Single & 0 & 0.0 & 0 & 0.0 & 2 & 8.0 & & 1 & 3.1 & 1 & 11.1 & 0 & 0.0 & \\
\hline \multicolumn{15}{|l|}{ Work } \\
\hline Work & 3 & 42.9 & 5 & $\begin{array}{c}50 . \\
0\end{array}$ & 10 & 40.0 & 0.864 & 13 & 40.6 & 4 & 44.4 & 1 & 100.0 & 0.495 \\
\hline
\end{tabular}


Tanta Scientific Nursing Journal

\begin{tabular}{|c|c|c|c|c|c|c|c|c|c|c|c|c|c|c|}
\hline House wife & 4 & 57.1 & 5 & $\begin{array}{c}50 . \\
0\end{array}$ & 15 & 60.0 & & 19 & 59.4 & 5 & 55.6 & 0 & 0.0 & \\
\hline Residance & & & & & & & & & & & & & & \\
\hline Rural & 0 & 0.0 & 2 & $\begin{array}{c}20 . \\
0\end{array}$ & 1 & 4.0 & \multirow{2}{*}{0.182} & 3 & 9.4 & 0 & 0.0 & 0 & 0.0 & \multirow{2}{*}{0.604} \\
\hline Urban & 7 & 100.0 & 8 & $\begin{array}{c}80 . \\
0\end{array}$ & 24 & 96.0 & & 29 & 90.6 & 9 & 100.0 & 1 & 100.0 & \\
\hline \multicolumn{15}{|l|}{$\begin{array}{l}\text { Education } \\
\text { level }\end{array}$} \\
\hline $\begin{array}{l}\text { Basic } \\
\text { education }\end{array}$ & 1 & 14.3 & 1 & $\begin{array}{c}10 . \\
0\end{array}$ & 9 & 36.0 & \multirow{3}{*}{0.199} & 8 & 25.0 & 3 & 33.3 & 0 & 0.0 & \multirow{3}{*}{0.775} \\
\hline $\begin{array}{l}\text { Secondary } \\
\text { education }\end{array}$ & 5 & 71.4 & 4 & $\begin{array}{c}40 . \\
0\end{array}$ & 8 & 32.0 & & 13 & 40.6 & 3 & 33.3 & 1 & 100.0 & \\
\hline University & 1 & 14.3 & 5 & $\begin{array}{c}50 . \\
0\end{array}$ & 8 & 32.0 & & 11 & 34.4 & 3 & 33.3 & 0 & 0.0 & \\
\hline \multicolumn{15}{|l|}{$\begin{array}{l}\text { Family } \\
\text { relation }\end{array}$} \\
\hline Strong & 4 & 57.1 & 5 & $\begin{array}{c}50 . \\
0\end{array}$ & 9 & 36.0 & \multirow{3}{*}{0.255} & 15 & 46.9 & 2 & 22.2 & 1 & 100.0 & \multirow{3}{*}{0.153} \\
\hline Moderate & 1 & 14.3 & 5 & $\begin{array}{c}50 . \\
0\end{array}$ & 13 & 52.0 & & 15 & 46.9 & 4 & 44.4 & 0 & 0.0 & \\
\hline Weak & 2 & 28.6 & 0 & 0.0 & 3 & 12.0 & & 2 & 6.3 & 3 & 33.3 & 0 & 0.0 & \\
\hline \multicolumn{15}{|l|}{$\begin{array}{l}\text { Friend } \\
\text { relation }\end{array}$} \\
\hline Strong & 3 & 42.9 & 7 & $\begin{array}{c}70 . \\
0\end{array}$ & 10 & 40.0 & \multirow{3}{*}{0.395} & 15 & 46.9 & 5 & 55.6 & 0 & 0.0 & \multirow{3}{*}{0.698} \\
\hline Moderate & 3 & 42.9 & 3 & $\begin{array}{c}30 . \\
0\end{array}$ & 9 & 36.0 & & 11 & 34.4 & 3 & 33.3 & 1 & 100.0 & \\
\hline Weak & 1 & 14.3 & 0 & 0.0 & 6 & 24.0 & & 6 & 18.8 & 1 & 11.1 & 0 & 0.0 & \\
\hline
\end{tabular}




\section{Tanta Scientific Nursing Journal}

\section{Discussion}

The potential psychological benefit of exercise training for stressed older adults includes improvement in cognitive functions, psychological wellbeing, mood, and socialization. Physical exercise may be efficient in reducing stress among the aged, regular exercise or physical activities program help individual to promote cognitive function along with mental wellbeing with sense of purpose in ones $\operatorname{life}^{(19) .}$

Panton who found that exercise is safe. However, helping the older adult to follow a few safety recommendations can help them stay injury free and active. Prior to starting an exercise program, the safety maintained with the older adult, who should be encouraged to ask questions and raise any safety concerns ${ }^{(\mathbf{2 0}) \text {. }}$

The older people are fragile and sensitive to life events stressors which increase risk for multiple physical and psychological distress. The present studied proved that provation for physical activity program to deescalate level of stress among older women.

The present study found that three quarter of the studied sample their ages ranged from 60 to 74 years and more than half of them were widow. As regards educational level, (40.5\%) had secondary school. Concerning residence the vast majority of them $(92.9 \%)$ live in the urban area. According to occupation, more than half of studied sample(57.1\%)were retired. Regarding family relation it was observed that more than third of studied sample (45.2\%) had moderate family relation, while friends relation near to half $(47.6 \%)$ were strong relation.

It is common to see older people in different research setting with similar demographic characteristics. Ble A. et al who studied effect of executive function correlates with walking speed in older persons describe the average age of participant was 86.3 (21). while Fernando de Andréa1 et.al. who mentioned the effect of physical activity on older people describe the participants age of the 18 elderly people varied from 60 to 89 years, with mean 74.5 years.A positive effect of exercise program on physical, mental and cognitive functions was proved as well as on social life of seniors(22).

In the same context, Neal Krause et.al., who found that the high score on the variable assessing gender denotes women while a high score on the education measure reflects more years of completed schooling. 


\section{Tanta Scientific Nursing Journal}

Moreover, a high score represents more physical health problems, greater financial difficulty. more negative interaction, more frequent exercise. and more stress symptoms (23).

The present study show that more than half of studied sample have high stress level and only $16.7 \%$ of them had low stress level. This should not be surprising as some individuals utilize exercise to cope with stress. Several other factors may moderate stress and physical activity relationships, such as stages of change for exercise. Habitually active individuals exercise more in the confront of stress. In recent years, we can also see a low intensity physical activity among old age people related to technology used as remote of $\mathrm{TV}$, retirement and physiological change which affect general health condition.

The present study paralleled with Matthew et al., who found that one hundred sixty eight studies that examined the influence of stress on physical activity among old age. the majority of which indicated that psychological stress predicts less physical activity (behavioral inhibition) and exercise two third percent sedentary behavior. Both objective (i.e., life events) and subjective (i.e., distress) measures of stress related to reduced physical activity. Prospective studies investigating the effects of objective markers of stress nearly all agreed (six of seven studies) that stress has a negative effect on physical activity among old age ${ }^{(24)}$. In same author studies examining older adults (>50 years), cohorts with both men and women, and larger sample sizes ( $\mathrm{n}>$ 100) were more likely to show an inverse association. $85.7 \%$ of higher-quality prospective research ( $\geq 7$ on a 9-point scale) showed the same trend. Interestingly, some prospective studies (18.2\%) report evidence that physical activity was positively impacted by stress.

The present study show that there was statistically significant difference $(\mathrm{p}<0.001)$.was found between pre and post physical activities program on stress level among older women. It might be regular exercising affects the good health of old age people allowing them not only quality physical work, but it also improves their condition. According to Nováková Svatava et al., who found the effect of physical activities on stress reduction among old age describe that the physical active elderly people have a positive influence on stress level experiences. In old age, physical activity is very important for 


\section{Tanta Scientific Nursing Journal}

the maintenance of life quality, especially in physical and psychological function ${ }^{(25) .}$

On the other hand the study by Pelcová and

Blaha reported that there is a correlation between the intense and moderately intense physical activity and stress reduction among elderly women (26).

In the same context, Wojtek J. et.al., who added that, a physical activity intervention to be successful in treatment of older adults must include regular physical activity is associated with significant improvements in overall psychological health and well-being. Both higher physical fitness and participation are associated with a decreased risk for stress, depression or anxiety. Exercise and physical activity have indices of psychosocial control, self-efficacy, and perceived competency ${ }^{(27) .}$

Consequently, stress may have a differential impact on exercise adoption, maintenance, and relapse. Preliminary evidence suggests that combining stress management programming with exercise interventions may allay stress-related reductions in physical activity, though rigorous testing of these techniques has yet to be produced ${ }^{(24) .}$

\section{Conclusion}

Based on the results of the present study, it can be concluded that, There was improvement in physical health, elevate stressors for elderly women. Elderly women will be able to use of physical activity to elevate stressors.

\section{Recommendations}

Based on the previous finding of the present study, recommended that: Physical exercises to be apart of activities of daily living for elderly women and health education for elderly women about important of regular Physical exercises.

\section{Reference:}

1.Butler, Alia. Stress, Anxiety \& Coping aman elderly Retrieved on from livestrong.com/article/127511-stressanxiety-coping 2013 .

2. Barnes N. Jill G.Exercise, cognitive function, and aging, Adv Physiol Educ.2015; 9(2): 55-62. doi: 10.1152/ advan.00101., PMC4587595, PMID: 26031719.

3.Lotan A, Lifschytz T, Wolf G, Keller S, Ben-Ari H, Tatarsky. Differential effects of chronic stress in young-adult and old female mice: cognitive-behavioral manifestations and neurobiological correlates, Molecular Psychiatry, doi:10.1038/mp.2017.237.

4.American Institute of Stress.Shepherd's Staff In-home Care, Senior Health \& 


\section{Tanta Scientific Nursing Journal}

Lifestyles2017 Available at https://www. cdc.gov/niosh/docs/87-111/

5.Karen Larson . The Association Between

Perceived Stress and Mortality Among People With Multimorbidity: A Prospective Population-Based Cohort Study, American Journal of Epidemiology, 2016;184(3): 199-210, https://doi.org/10.1093/aje/kwv324

6.Kolehmainen and Sinha. The effects of stress on physical activity and exercise published in final edited form as: Sports Med.2015; 44(1): 81-121. doi: 10.1007/s40279-013-0090-5.

7.Babu Paikkatt, Amool Ranjan Singh, Pawan Kumar Singh, and Masroor Jahan. Efficacy of yoga therapy on subjective well-being and basic living, over looked http://www.ncbi.nlm.nih.gov.2012

8.Chiesa, A., and A. Serretti. Mindfulnessbased stress reduction for stress management in healthy people: a review and meta-analysis." Journal of Alternative Complementary Medicine 15.5 May 2009: 593-600.

9.Maaike A, Geert A, Verhaar H, Aleman A, Luc V.Physical activity and enhanced fitness to improve cognitive function in older people without known cognitive impairment. Cochrane Database Syst Rev2008; 2:1-37.

10. Plassman BL, Williams J, Burke JR, Holsinger T, Benjamin S. Systematic review: factors associated with risk for and possible prevention of cognitive decline in later life. Ann Intern Med.2010; 153:182-193.

11. World Health Organization (WHO): physical activity in elderly2015Available at www.who.int

12. Kendal A. Types of Physical Activities for Older Adults2015Available at www.kendalathome.org

13. Gorczynski, P., \& Faulkner G., Exercise therapy for elderly Available at www.summaries.cochrane.org2011

14. Anxiety and Depression Association of America. Physical Activity Reduces Stress, Conference - April 58,Washington Marriott Wardman Park Hotel, Washington, DC. 2018

15. Blahutková M., Jonášová D., Ošmera M.. Duševní zdraví a pohyb. Brno: CESA VUT v Brně, Aaktivity. ISBN 2015;978-80-7204-916-5.

16. First 30 days .Perception of life stressors questioners2008 .Available at www.first 30 days.com 
17. Holmes Thomas and Rahe Richard. Social Readjustment Rating Scale, Journal of Psychosomatic Research. 1967;1 II(1):5

18. SPSS Inc. PASW Statistics for Windows, Version 18.0. Chicago, 2015 Available at https://www-01.ibm.com

19. Sjosten \& Kivela . The effects of physical exercise on depressive symptoms among the aged: a systematic review, Int $\mathrm{J}$ Geriatr Psychiatry. May 2006;21(5):410-8.

20. Panton. Exercise for older adults 2001 Available at www.apta.org

21. Ble A. Executive Function Correlates with Walking Speed in older persons, in CHIANTI Study. Journal of the American Geriatric Society 2005;53 (1):410-415. Brno: Motiv Press.

22. Fernandode Andréa1,FernandaVarkala Lanuez,AdrianaNunes Machado,Wilson Jacob Filho: Physical activity and stress coping in the elderly , version ISSN 2010.1679-4508 Online version ISSN 2317 - 6385, Einstein (São Paulo) vol.8 no.4 São Paulo.

23. Neal Krause, Goldenhar Linda, Lianc Jersey, Jay Gina and Mmaeda Daisaku. Stress and exercise among the Japanese elderly, Sot. Sci. Med.1993; 36 ( II): 1429-1441, Printed in Great Britain.
24. Matthew A. Stults-Kolehmainen and Rajita Sinha (2015): The Effects of Stress on Physical Activity and

Exercise among old age, Published in final edited form as:Sports Med. 44(1): 81-121. doi: 10.1007/s40279-0130090-5

25. Nováková Svatava, Blahutková Marie, Muchová Marta, Lepková Hana. Influence of Physical Activities on Stress Reduction among Third Age University Students, PRACE NAUKOWE Akademi i im. Jana Długosza w Częstochowie Kultura Fizyczna, t. XV,2016 nr 4, s. 183-193 http://dx.doi.org/10.16926/kf.2016.15.40

26. Pelclova J., Blaha L. Is PedometerDetermined Physical Activity Decreasing in Czech Adults? Findings from 2008 to 2013. Int J Environ Res Public Health. Oct 24-2013;;13(10): 1040.

27. Wojtek J. Chodzko-Zajko, Ph.D., FACSM, David N. Proctor, FACSM, Maria A. Fiatarone Singh, Christopher T. Minson, FACSM; Claudio R. Nigg, George J. Salem, FACSM; and James S. Skinner, FACSM: Exercise and physical activity for older adults, Journal of the American College of Sports Medicine http available at www.acsm-msse.org 2009. 